\title{
An ECM-ISC Based on College Students' Continued Learning Intention toward E-Learning Space Post COVID-19
}

\author{
Wei Wang1,2, Yuexin Duan,2, Qing Wang², Hehai Liu² \\ ${ }^{1}$ Templar School of Education, Johnson University, Knoxville, USA \\ ${ }^{2}$ College of Educational Sciences, Anhui Normal University, Wuhu, China \\ Email: 545896278@qq.com, 13359083905@163.com,510879237@qq.com,358383418@qq.com
}

How to cite this paper: Wang, W., Duan, Y. X., Wang, Q., \& Liu, H. H. (2021). An ECM-ISC Based on College Students' Continued Learning Intention toward E-Learning Space Post COVID-19. Open Journal of Social Sciences, 9, 377-395.

https://doi.org/10.4236/jss.2021.912026

Received: December 3, 2021

Accepted: December 20, 2021

Published: December 23, 2021

Copyright $\odot 2021$ by author(s) and Scientific Research Publishing Inc. This work is licensed under the Creative Commons Attribution International License (CC BY 4.0).

http://creativecommons.org/licenses/by/4.0/ (c) (i) Open Access

\begin{abstract}
The "Suspending Classes without Stopping Learning", which is an emergency policy launched by the Chinese government to continue teaching activities as schools across the country, gives a new opportunity to popularize the application of E-learning space for college students. In order to explain college students' continued learning intention toward E-learning space post COVID-19, this study combines theories from the fields of ECM-ISC (Expectation Confirmation Model for Information Systems Continuance). By adding two latent variables, namely students' initial intention and teacher guidance factor, an improved ECM-ISC model for college students' continued learning intention was put forward. Results from Linear regression analysis and structural equation modeling (SEM) demonstrate a strong explanatory power of the new model. Based on the results of the empirical analysis, corresponding suggestions are proposed.
\end{abstract}

\section{Keywords}

ECM-ISC, Post COVID-19, Continued Learning Intention, E-Learning Space, SEM

\section{Introduction}

At the beginning of 2020, the COVID-19 suddenly broke the regular teaching in person, and schools in all regions responded to the call of the Ministry of Education of China to "suspend classes without stopping learning". This is undoubtedly the most extensive, longest paced, and most enthusiastic popularization of E-learning space. As noted in the 48th China Internet Network Development 
Statistics Report released by the China Internet Information Center, the number of online education users in China has reached 325 million as of June 2021 (China Internet Information Center, 2020).

After the return to regular daily teaching in person, how to continually use the E-learning space well and how to bring into play the continuous positive benefits of the E-learning space has drawn the key attention of researchers. On this basis, this study is intended to carry out an empirical analysis on the continuous intention to use E-learning space of college students post Covid-19, specifically the following aspects. Firstly, the study examines the variability of demographic variables on college students' intention to continuous use E-learning space. Second, based on the ECM-ISC model, this study explored the direct effects of perceived ease of use, perceived usefulness, expectation confirmation, satisfaction, college students' initial intention, and teachers' guidance factor on college students' intention to consistently use E-learning space. Third, linear regression and structural equation models are constructed to investigate the quantitative relationships between each latent variable and college students' intention to continuous use E-learning space. Finally, the results of the empirical analysis are attributed and discussed, and relevant suggestions are proposed.

\section{Literature Review}

\subsection{Information Systems Continuous Use Study}

In 1986, Davis (1986) proposed the first systematic TAM (Technology Acceptance Model) in his dissertation followed by the more systematic and comprehensive TM (Davis, 1989) model in 1989, which takes perceived ease of use and perceived usefulness as the core variables that determine information system users' intention to continue using information systems. By systematically analyzing the factors that affect information system users' behavioral intentions, especially perceived ease of use and perceived usefulness, the TAM series of models can well predict information system users' continuous use behavior. In 2001, Bhattacharjee observed and empirically validated the information system persistence behavior of online banking users, drawing on the TAM and ECM models, focusing on the study of information system users' persistent intention after initial acceptance, and the latent variables are all post-user initial usage variables, the ECM-ISC model was proposed (Bhattacherjee, 2001).

From Figure 1, users' intention to continue using information systems is influenced by three factors: "perceived usefulness", "expectation confirmation", and "satisfaction". The perceived usefulness of the information system positively influences the users' intention to continue using the system; the users' satisfaction is influenced by the expectation confirmation and the perceived usefulness, which positively influences the users' intention to continue using the system; the expectation confirmation indirectly influences the users' intention to continue using the system by affecting the users' perceived usefulness and satisfaction. For the study of the persistence behavior of information system, only focusing on the 


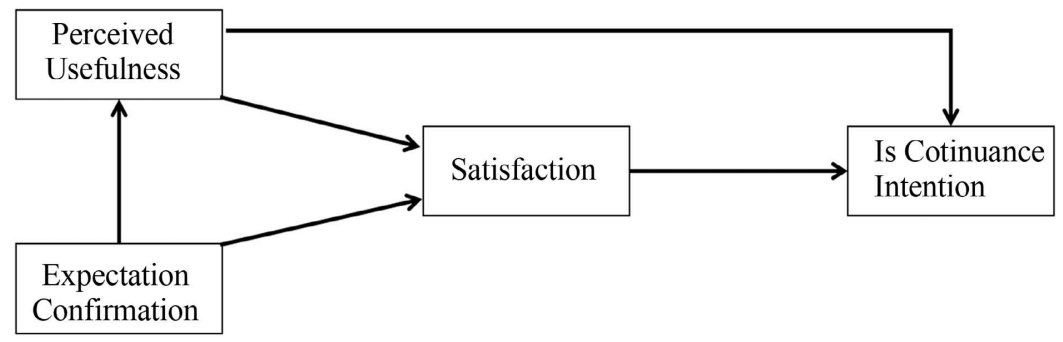

Figure 1. Bhattacharjee information system continuous use model.

initial acceptance intention of users does not determine the persistence behavior of information system users. Lin et al. (2005) verified that the initial persistence intention of information system users does not significantly affect their final persistence purchase behavior in a study on the purchase persistence behavior of online shopping website users. Limayem (2007) introduced user habits in 2007 to extend the original continuous use model and began to focus on the continuous use behavior for information systems; Bhattacherjee et al. (2008) introduced the key variables of convenient conditions and self-efficacy in 2008, while removing the direct effect of perceived usefulness on satisfaction and proposed an extended model of ECM-ISC (Bhattacherjee et al., 2008) to increase the applicability of the model. This is shown in the following figure.

From Figure 2, IT users' self-efficacy indirectly affects their continuous use behavior by influencing information system users' intention to continuously use, and convenience can directly affect information system users' continuous use behavior. Since then, many foreign scholars based on this model have added different latent variables based on the actual studied information systems to explore the influence of these added latent variables on information system users' intention of sustained behavior, for example, Shiau, Wen-Lung, \& Luo (2013) explored the factors affecting the sustained intention of popular hedonic information system blogs, and finally found that integrating perceived entertainment and user engagement into the information system persistent use model can better explain blog persistent use behavior. Park, Ji-Hong (2014) introduced Perceived conversion cost to explore the persistent use behavior of social networking site (SNS) users and found that personalization increases their Perceived conversion cost and satisfaction, which leads to further persistent use of SNS, and suggested that when adding personalization features to SNS, it is necessary to consider user Perceived conversion cost. Turel \& Gefen (2013) introduced trust into the information system continuous use model and showed that trust can not only directly influence the intention of information system users, but also indirectly influence the intention of continuous use by promoting social investment in the relationship with the system and its users. Ouyang et al. (2017) systematically sorted out the research use of the ECM-ISC model in foreign countries and found that the use of the extended ECT-ISC model mainly expanded the core latent variables of the information system continuous use model in the three dimensions of users, environment, and system. 


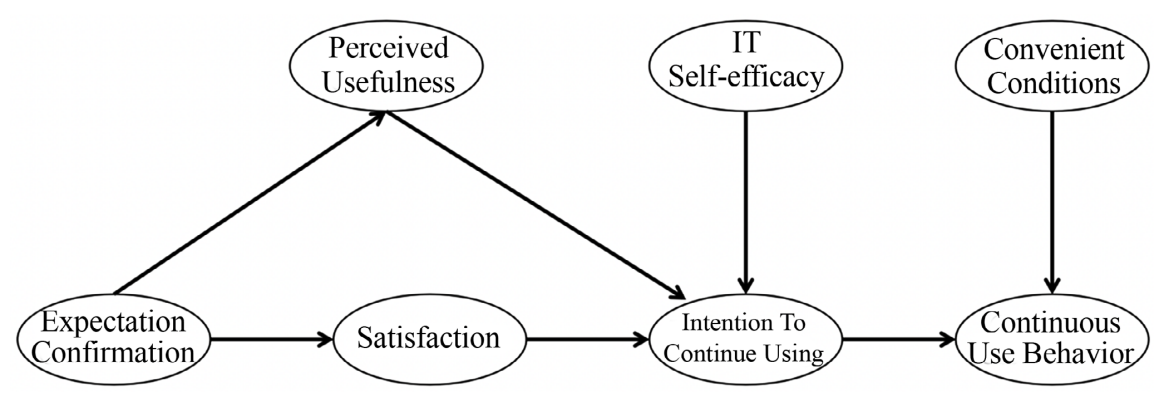

Figure 2. Extended information system continuity of use model.

In China, the ECM-ISC model mainly concentrated in the fields of library and intelligence science and economic management, and there are fewer empirical studies in the field of education. Based on the behavioral characteristics of mobile users, Liu \& Sun (2011) found that the self-efficacy of mobile search users affects their continuous use intention. Li \& Guo (2017) explored that for the users of archival WeChat, their habits, interests, higher expectations and subsequent demands can directly trigger their continuous use behavior. Hang Weiwei (2017) conducted an empirical analysis through the data collection of crowdsourcing community users, found that satisfaction is the most significant factor to affect their continued using behavior. Yang (2015) introduced the variables related to resource quality and service quality into the extended model based on the relevant characteristics of digital education learners to demonstrate that information system quality and service quality affect the degree of expectation confirmation to further influence the continuous use of digital resource user's intention.

\subsection{Research Related to E-Learning Space}

In April 2018, China's Ministry of Education (2019) released the Guidelines for the Construction and Application of E-learning Space which clearly defines an E-learning space as a legal-name E-learning place that is recognized by educational authorities or schools, integrates resources, services, and data, and supports sharing, interaction, and innovation. Combined with the practical application of E-learning space for college students, this study defines E-learning space for college students in a narrow sense as a comprehensive E-learning platform that provides daily teaching, learning resources, teacher-student interaction, partner communication, learning evaluation and personal learning data management functions for college students. In recent years, most domestic scholars have focused on the theory, design, and application of E-learning space.

Zhu Zhiting (2013) constructed the overall framework of E-learning space by integrating the connotation analysis of "space for all". Yang \& Wu (2016) proposed the application model of E-learning space from the perspective of ubiquitous learning. Yang \& Wang (2018) constructed the teaching application of DPSC (Develop Problem Solving Capability). Xie et al. (2016) explored the effect of E-learning space on self-efficacy enhancement in the context of a research 
methods course on educational technology for college students. Studies on the continuous use of E-learning space focus on the factors influencing the acceptance, satisfaction, and intention to continue using E-learning space. Based on the UTAUT (Unified Theory of Acceptance and Use of Technology) model, Zhang (2016) investigated the factors of primary and secondary school teachers' use of E-learning space, and the study showed that performance expectations, social influence, and convenience had positive effects on teachers' behavioral tendency to use E-learning space, and the effect of effort expectations on teachers' behavioral tendency was not significant. Xu \& Zhu (2019) conducted an empirical study based on the theory of planned behavior on vocational college students' use of E-learning space, the results showed that acceptance of E-learning space of vocational colleges was at a moderate to high level, and attitudes, subjective norms, and perceived behavioral control all had significant positive effects on their behavioral intentions. Yong (2018) found that students' IT skill level, E-learning space system design, course design and E-learning space extension resources positively predicted students' learning satisfaction. Chen et al. (2014) verified that the value of perceived mobility is also a key factor influencing mobile users' intention to continue to use the E-learning space. The study showed that the interactivity of the interface and content in the E-learning space affects the satisfaction of E-learning and eventually positively affects students' intention to continue using the learning.

In summary, the ECM-ISC model has been widely used in studies related to the continuous use intention of information system users, with particular attention to the continuous use intention after the initial adoption. The E-learning space can be regarded as an information system with the functions of resource transfer, information sharing and data interaction, and the users of this information system are teachers and students in the E-learning space. Considering the special characteristics of college students' continuous use behavior during the period of "stopping classes without stopping learning", this study takes college students' intention of continuous use as the last observed continuous use decision variable.

\section{Research Model and Research Hypothesis}

\subsection{Establishment of the Research Model}

In the transition from "space for all" to "space for all using", the intention to use the E-learning space has become a key element. In this study, the factors influencing the continued use of information systems established in E-learning space were divided into initial intention to use, external facilitators, and internal facilitators.

The initial intention to use factor refers to the intention of college students to use the E-learning space before they use it, and it reflects to a certain extent the college students' acceptance of the E-learning space, which is a pre-continuous use variable. External facilitators refer to the external factor that guide college 
students to use E-learning space. E-learning space is different from general information systems, and teachers have an important influence on students' intention to use it, so the teacher guidance factor is taken as an external facilitating variable for college students' intention to use E-learning space continuously.

According to the research on the continuous use of information systems conducted by domestic and foreign scholars, after the initial adoption of the information system, the continuous use intention of users is mainly influenced by four core internal facilitators: perceived ease of use, perceived usefulness, expectation confirmation, and satisfaction. The perceived ease of use reflects how easy the information system users think it is. In this study, the perceived ease of use of the E-learning space is classified as easy to operate the space, easy to access resources, easy to learn skills; the perceived usefulness reflects how much the information system users think the system helps them improve, and in this study, it refers to how much the E-learning space helps college students improve their learning, which is specifically classified as useful resources, useful interaction, useful evaluation.

The expectation confirmation refers to the comparison of the expectations of information system users before and after using the information system, and the degree of expectation confirmation of college students using the E-learning space is divided into experience confirmation, function confirmation, and overall expectation confirmation; satisfaction refers to how users are satisfied with the information system, and the satisfaction of college students with the E-learning space is divided into satisfaction of functional needs, satisfaction of resource needs, and satisfaction of using experience. In addition, according to ECM-ISC, perceived usefulness and satisfaction, as mediating variables, have an important moderating effect on information system users' intention to use continuously to a certain extent. Therefore, based on the information system continuous use model and the relevant characteristics of the E-learning space, we determine the composite research model, as shown in Figure 3, and put forward the corresponding hypotheses according to the model.

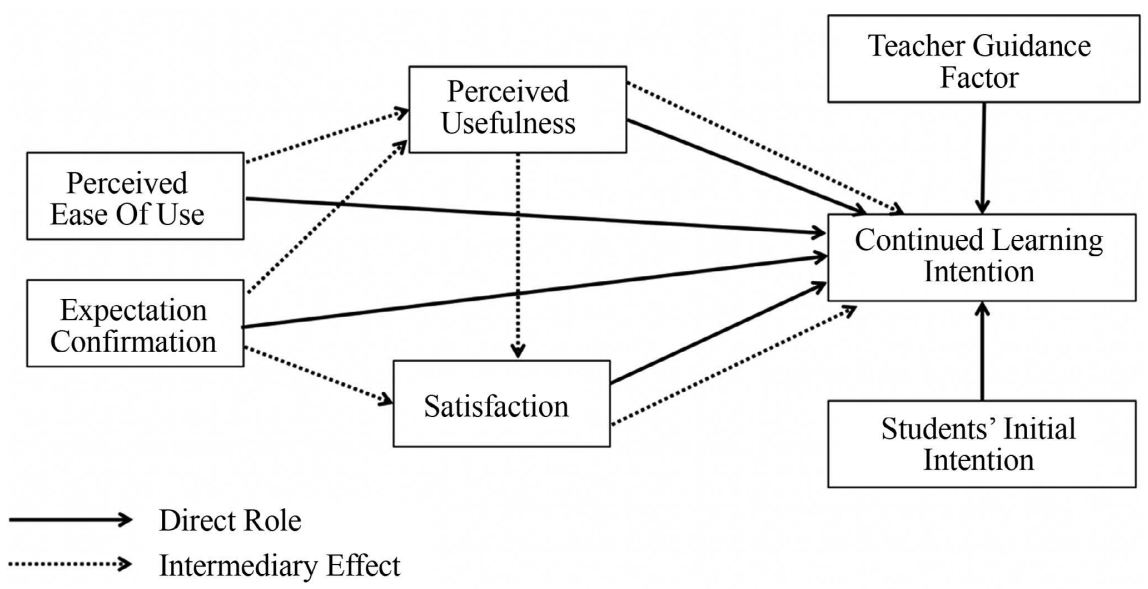

Figure 3. Composite study model. 


\subsection{Research Hypothesis}

\section{Direct action model hypothesis}

Hypothesis 1 (H1): Perceived Ease of Use (PEU) positively influences college students' intention to use E-learning space consistently.

Hypothesis 2 (H2): Expectation Confirmation (EC) positively influences college students' intention to use E-learning space consistently.

Hypothesis 3 (H3): Perceived Usefulness (PU) positively influences college students' intention to use the E-learning space consistently.

Hypothesis 4 (H4): Satisfaction (STF) positively influences college students' intention to use the E-learning space consistently.

Hypothesis 5 (H5): Teacher Guidance Factor (TGF) positively contributes to college students' intention to use the E-learning space consistently.

Hypothesis 6 (H6): Students' Initial Intention (SII) positively promotes college students' intention to use the E-learning space consistently.

\section{Mediating effect model hypotheses}

Perceived usefulness mediating effect hypothesis.

Hypothesis 7 (H7): perceived ease of use (PEU) promotes college students' intention to use E-learning space consistently through the mediating effect of perceived usefulness (PU).

Hypothesis 8 (H8): expectation confirmation (EC) promotes college students' intention to use the E-learning space consistently through the mediating role of perceived usefulness (PU).

Satisfaction-mediated effect hypothesis.

Hypothesis 9 (H9): perceived usefulness (PU) promotes college students' intention to use E-learning space consistently through the mediating effect of satisfaction (STF).

Hypothesis 10 (H10): expectation confirmation (EC) promotes college students' intention to use E-learning space consistently through the mediating effect of satisfaction (STF).

Chain mediating effect of perceived usefulness and satisfaction hypothesis.

Hypothesis 11 (H11): perceived ease of use (PEU) promotes college students' intention to use E-learning space consistently through the chain-mediating effect of perceived usefulness satisfaction (PU-STF).

Hypothesis 12 (H12): expectation confirmation (EC) facilitates college students' intention to use E-learning space consistently through the chain-mediating effect of perceived usefulness and satisfaction (PU-STF).

In addition to the above hypotheses, the gender, grade, and major category of the interviewed college students were also included in the consideration of influencing the intention to use consistently.

\subsection{Empirical Study}

\section{Questionnaire Design and Collection}

After determining the above research model and hypothesis, the data collec- 
tion of this study was conducted by questionnaire. The questionnaire consists of three parts: basic information of college students, potential variables measurement questions and open-ended questions.

The basic information of the subjects includes gender, grade, major category and the basic usage of E-learning space; the questions of potential variables measurement questions are in the form of a five-level Likert scale, and the respondents are asked to choose among the options of "very unlikely, unlikely, average, and very likely" according to their actual experience of using E-learning space. The open-ended questions were designed to capture the subjective needs of college students by understanding the changes they expect in the E-learning space. To avoid semantic repetition of questions and to ensure the aggregation and discriminant validity of the questionnaire items, a pilot test was conducted before the formal distribution of the questionnaire. The test subjects were 30 college students of different majors in a normal university. After the test, the items that caused repetition in semantics and structure were deleted, and then the final questionnaire was modified by consulting with relevant experts.

The questionnaires were distributed online based on the social science survey report of the 9th "Challenge Cup" Student Extra-curricular Academic Science and Technology Works Competition, with college students from 11 provinces including Guangdong, Fujian, Anhui, Jiangxi, Shandong and Sichuan. 209 samples were taken for final research and analysis after stratified sampling.

\section{Descriptive statistical analysis}

The data from the questionnaire were entered into SPSS24.0 for descriptive analysis, and it shows that the average intention of college students to use E-learning space consistently was 3.45 , which is a medium to high level, and among all latent variables, the standard deviation of intention to use consistently was the largest, with a value of 0.72 , indicating that there was a large variation in the overall intention of college students to use E-learning space consistently, and the standard deviation value of teachers' guidance factor was the smallest, with a value of 0.55 . The means and standard deviations of the remaining latent variables are shown in Table 1.

As can be seen from the above table, the mean of each latent variable is stable between 3.29 and 3.52, and the standard deviations of the remaining items are stable between 0.55 and 0.72 , indicating that the overall variability of these latent variables tends to be stable and the scores of each are reasonably extended around the mean.

\section{Reliability and validity analysis}

Reliability analysis is used to determine the level of reliability of the questionnaire, Validity analysis refers to the accuracy of the questionnaire, consisting of content validity, criterion validity, and structural validity. In this study, Cronbach's alpha coefficient with SPSS 24.0 was used for reliability testing; validity testing was performed with validated factor analysis with AMOS 26. The structural validity of the questionnaire data is shown in Table 2. 
Table 1. Descriptive statistics of latent variables.

\begin{tabular}{ccccccc}
\hline Latent variable & $\begin{array}{c}\text { Measure } \\
\text { Items }\end{array}$ & $\begin{array}{c}\text { minimum } \\
\text { value }\end{array}$ & $\begin{array}{r}\text { maximum } \\
\text { average } \\
\text { value }\end{array}$ & $\begin{array}{c}\text { standard } \\
\text { deviation }\end{array}$ \\
\hline Students' initial intention (SII) & 3 & 1 & 5 & 3.29 & 0.66 \\
Teacher guidance factor (TGF) & 3 & 1 & 5 & 3.42 & 0.55 \\
Perceived ease of use (PEU) & 3 & 1 & 5 & 3.52 & 0.62 \\
Perceived usefulness (PU) & 3 & 1 & 5 & 3.41 & 0.62 \\
Expectation confirmation (EC) & 3 & 1 & 5 & 3.40 & 0.68 \\
Satisfaction (STF) & 4 & 1 & 5 & 3.52 & 0.64 \\
continued learning intention (CLI) & 4 & 1 & 5 & 3.45 & 0.72 \\
\hline
\end{tabular}

Table 2. Structural validity test.

\begin{tabular}{ccccccc}
\hline$X_{2} / \mathrm{df}$ & RMSEA & CFI & NFI & GFI & IFI & TLI \\
\hline 2.129 & 0.074 & 0.937 & 0.902 & 0.892 & 0.938 & 0.924 \\
\hline
\end{tabular}

As shown in Table 2, the $X_{2} / \mathrm{df}$ (chi-squared degrees of freedom ratio) is less than 3, the RMSEA (root-mean-square error of approximation) is less than the reference value 0.08 , and the GFI value is close to 0.9 ; in addition, the CFI, IFI, TLI, and NFI are greater than the reference standard value $(\mathrm{Wu}, 2009) 0.9$, indicating the model is reasonably fit.

CR (Construct Reliability) reflects whether all measure items in each latent variable consistently explain the latent variable. AVE (Average Variance Extracted) measures convergent validity and represents the correlation between the latent variable and the measure items. The standardized path coefficients between the latent variable and the measured item are used to calculate the CR and the AVE. When the value of CR and AVE values are high, it indicates better convergent validity of the questionnaire data, and the results are shown in Table 3.

It shows that the factor loadings of each items range from 0.47 to 0.94 , which basically meet the reference standard of $0.5-0.95$ under the condition that the factor loadings are less than 0.05 at p-value; the AVE of each latent variable are greater than the reference value of 0.5 except for the teacher-guided factor which is slightly lower than 0.5 ; the value of CR are greater than 0.7 . The Cronbach's $\alpha$ coefficients were all greater than 0.75 , indicating that the data of the questionnaire had good convergent validity.

\subsection{Hypothesis Validation}

\section{Direct effect model validation}

To verify the direct effect of students' initial intention, teacher guidance factor, perceived ease of use, perceived usefulness, expectation confirmation, and satisfaction on college students' continuous use of E-learning space, a hierarchical linear regression was used to explore the linear quantified relationship of 
Table 3. Convergence validity test.

\begin{tabular}{|c|c|c|c|c|}
\hline Items & Path coefficient & AVE & $\begin{array}{l}\text { Combination } \\
\text { reliability }(\mathrm{CR})\end{array}$ & $\begin{array}{l}\text { Cronbach's } \\
\text { a coefficient }\end{array}$ \\
\hline SII3 & 0.67 & \multirow{3}{*}{0.51} & \multirow{3}{*}{0.76} & \multirow{3}{*}{0.754} \\
\hline SII2 & 0.77 & & & \\
\hline SII1 & 0.70 & & & \\
\hline TGF3 & 0.57 & \multirow{3}{*}{0.48} & \multirow{3}{*}{0.71} & \multirow{3}{*}{0.657} \\
\hline TGF2 & 0.47 & & & \\
\hline TGF1 & 0.94 & & & \\
\hline PEU3 & 0.88 & \multirow{3}{*}{0.69} & \multirow{3}{*}{0.87} & \multirow{3}{*}{0.863} \\
\hline PEU2 & 0.82 & & & \\
\hline PEU1 & 0.78 & & & \\
\hline PU3 & 0.79 & \multirow{3}{*}{0.65} & \multirow{3}{*}{0.85} & \multirow{3}{*}{0.847} \\
\hline PU2 & 0.75 & & & \\
\hline PU1 & 0.88 & & & \\
\hline EC3 & 0.80 & \multirow{3}{*}{0.74} & \multirow{3}{*}{0.89} & \multirow{3}{*}{0.887} \\
\hline EC2 & 0.87 & & & \\
\hline $\mathrm{EC} 1$ & 0.90 & & & \\
\hline STF4 & 0.87 & \multirow{4}{*}{0.74} & \multirow{4}{*}{0.92} & \multirow{4}{*}{0.917} \\
\hline STF3 & 0.86 & & & \\
\hline STF2 & 0.85 & & & \\
\hline STF1 & 0.85 & & & \\
\hline CLI4 & 0.87 & \multirow{4}{*}{0.76} & \multirow{4}{*}{0.93} & \multirow{4}{*}{0.927} \\
\hline CLI3 & 0.81 & & & \\
\hline CLI2 & 0.89 & & & \\
\hline CLI1 & 0.92 & & & \\
\hline
\end{tabular}

each potential variable on the intention of continuous use, and the results of the SPSS correlation test were done for each latent variable before regression testing as shown in Table 4.

It shows that students' initial intention, perceived ease of use, perceived usefulness, expectation confirmation and satisfaction are significantly correlated with college students' intention to continuously use E-learning space (correlation coefficients $r=0.479-0.812$, $\mathrm{p}$ value are all significantly correlated at the 0.01 level), where the correlation coefficient between satisfaction and continuous use $\left(0.812^{\star *}\right)$ is the highest, the correlation coefficient between students' initial intention and continuous use $\left(0.479^{* *}\right)$ is the lowest, and teacher guidance factor $(0.107)$ were not significantly correlated with continued learning intention. 
Table 4. Correlation test of latent variables.

\begin{tabular}{|c|c|c|c|c|c|c|}
\hline & $\begin{array}{l}\text { Students' initial } \\
\text { intention } \\
\text { (SII) }\end{array}$ & $\begin{array}{c}\text { Teacher } \\
\text { guidance } \\
\text { factor (TGF) }\end{array}$ & $\begin{array}{c}\text { Perceived ease } \\
\text { of use } \\
\text { (PEU) }\end{array}$ & $\begin{array}{l}\text { Perceived } \\
\text { usefulness } \\
\text { (PU) }\end{array}$ & $\begin{array}{l}\text { Expectation } \\
\text { confirmation } \\
\text { (EC) }\end{array}$ & $\begin{array}{c}\text { Satisfaction } \\
\quad(\mathrm{STF})\end{array}$ \\
\hline Teacher guidance factor (TGF) & $0.225^{\star \star}$ & & & & & \\
\hline Perceived ease of use (PEU) & $0.515^{\star \star}$ & $0.269^{\star *}$ & & & & \\
\hline Perceived usefulness (PU) & $0.539^{\star *}$ & $0.270^{\star *}$ & $0.757^{\star \star}$ & & & \\
\hline Expectation confirmation (EC) & $0.401^{\star *}$ & $0.231^{\star *}$ & $0.646^{* *}$ & $0.713^{\star *}$ & & \\
\hline Satisfaction (STF) & $0.464^{* *}$ & $0.232^{* *}$ & $0.775^{\star *}$ & $0.808^{\star *}$ & $0.800^{\star *}$ & \\
\hline Continued Learning Intention (CLI) & $0.479^{\star *}$ & 0.107 & $0.692^{\star *}$ & $0.762^{\star *}$ & $0.715^{\star \star}$ & $0.812^{\star \star}$ \\
\hline
\end{tabular}

${ }^{* *}$ At 0.01 level (double tail), the correlation was significant.

After correlation analysis, the variables of gender, grade, and major category were recorded using SPSS 24.0 and categorized as independent variables in Model 1, with continued learning intention as the dependent variable. The variables of model 1 were categorized as model 2 by adding college students' initial intention, teacher guidance factor, perceived ease of use, and expected confirmation as independent variables, and gender, grade, and major category as control variables; model 2 was categorized as model 3 by adding perceived usefulness as independent variables; model 3 was categorized as model 4 by adding satisfaction as independent variables. After model collation, the predictor variables in each variable model were subjected to hierarchical linear regression after VIF co-linearity test, and the results are shown in Table 5.

As can be seen from Table 5, the VIF values of the latent variables of the four models analyzed layer by layer range from 1.04 to 4.80 , and the reference VIF values are supposed to be range from 1 to 10 , indicating that there is no co-linear relationship among the predictor variables of each model, and the linear regression model is acceptable. The F-value in linear model 1 was 0.331 and the $\mathrm{R}$-squared value was 0.005 , suggesting that there was no significant difference in the intention to continuously use E-learning space among college students of different gender, grade, and major categories.

The Beta values of teacher guidance factors in linear models 2, 3 and 4 are all negative, indicating that teacher guidance facilitation factors have no positive influence on college students' intention to continuously use E-learning space, and hypothesis 5 is not valid. The Beta values of students' initial intention are 0.131 , 0.068 and 0.073 respectively, significantly correlated by t-value test, indicating that students' initial intention has a positive influence on college students' intention to continuously use E-learning space, the hypothesis 6 is valid. The model Beta values of perceived ease of use were $0.373,0.208$, and 0.081 , which were significantly correlated by t-value test, indicating that the perceived ease of use positively influenced students' intention to continuously use the E-learning space, and hypothesis 1 is valid; the model Beta values of expectation confirmation were $0.459,0.319$, and 0.141 , which were significantly correlated by $t$-value 
Table 5. Linear regression model layer by layer.

\begin{tabular}{|c|c|c|c|c|c|c|c|c|c|c|c|c|}
\hline \multirow{3}{*}{ latent variable } & \multicolumn{3}{|c|}{ Model 1} & \multicolumn{3}{|c|}{ Model 2} & \multicolumn{3}{|c|}{ Model 3} & \multicolumn{3}{|c|}{ Model 4} \\
\hline & \multicolumn{3}{|c|}{$\begin{array}{c}\text { Continued } \\
\text { learning intention }\end{array}$} & \multicolumn{3}{|c|}{$\begin{array}{c}\text { Continued } \\
\text { learning intention }\end{array}$} & \multicolumn{3}{|c|}{$\begin{array}{c}\text { Continued } \\
\text { learning intention }\end{array}$} & \multicolumn{3}{|c|}{$\begin{array}{c}\text { Continued } \\
\text { learning intention }\end{array}$} \\
\hline & Beta & $\mathrm{t}$ & VIF & Beta & $\mathrm{t}$ & VIF & Beta & $\mathrm{t}$ & VIF & Beta & $\mathrm{t}$ & VIF \\
\hline constants & & 11.00 & & & 1.83 & & & 1.68 & & & 1.13 & \\
\hline gender & 0.005 & 0.07 & 1.13 & -0.034 & -0.74 & 1.15 & -0.04 & -0.94 & 1.15 & -0.036 & -0.91 & 1.15 \\
\hline Professional category & -0.06 & -0.81 & 1.14 & -0.001 & -0.03 & 1.15 & 0.002 & 0.05 & 1.15 & 0.029 & 0.71 & 1.16 \\
\hline grade & 0.045 & 0.63 & 1.04 & -0.065 & -1.46 & 1.08 & -0.046 & -1.11 & 1.08 & -0.044 & -1.13 & 1.08 \\
\hline SII & & & & $0.131^{\star * *}$ & 2.58 & 1.41 & $0.068^{\star * *}$ & 1.40 & 1.49 & $0.073^{* * *}$ & 1.59 & 1.49 \\
\hline TGF & & & & -0.124 & -2.78 & 1.10 & -0.137 & -3.26 & 1.10 & -0.128 & -3.25 & 1.10 \\
\hline PEU & & & & $0.373^{* * *}$ & 6.06 & 2.07 & $0.208^{* * *}$ & 3.18 & 2.66 & $0.081^{\star * *}$ & 1.24 & 3.05 \\
\hline $\mathrm{EC}$ & & & & $0.459^{* * *}$ & 8.12 & 1.75 & $0.319^{* * *}$ & 5.39 & 2.18 & $0.141^{\star * *}$ & 2.20 & 2.94 \\
\hline $\mathrm{PU}$ & & & & & & & $0.383^{\star * *}$ & 5.38 & 3.17 & $0.243^{\star * *}$ & 3.39 & 3.65 \\
\hline STF & & & & & & & & & & $0.445^{\star * *}$ & 5.43 & 4.80 \\
\hline $\mathrm{F}$ & & 0.331 & & & 49.543 & & & 2.987 & & & 7.073 & \\
\hline $\mathrm{R}^{\wedge} 2$ & & 0.005 & & & 0.633 & & & 0.679 & & & .721 & \\
\hline
\end{tabular}

test, indicating that the expectation confirmation positively influenced students' intention to continuously use the E-learning space., the hypothesis 2 is valid.

After adding perceived usefulness from model 3 and 4 , Beta values are 0.383 and 0.243 respectively, and the $t$-value test is significantly correlated, indicating that perceived usefulness positively affects college students' intention to use E-learning space continuously, and hypothesis 3 is valid; after adding satisfaction independent variable to model 4 , its Beta value is 0.445 , and the $t$-value test is significantly correlated, indicating that satisfaction positively affects college students' continued learning intention toward E-learning space, and hypothesis 4 is valid.

With the results of the stratum-by-stratum analysis, the variable of students' initial intention was set as $X_{1}$, the variable of teachers' guidance factor was set as $X_{2}$, the variable of perceived ease of use was set as $X_{3}$, the variable of expected confirmation was set as $X_{4}$, the variable of perceived usefulness was set as $X_{5}$, the variable of satisfaction was set as $X_{6}$, the dependent variable of continued learning intention was set as $Y$, the constant was set as $b$, and the error was set as $c$. The following linear equation could be obtained.

$Y=0.073 X_{1}+(-0.128) X_{2}+0.081 X_{3}+0.141 X_{4}+0.243 X_{5}+0.445 X_{6}+b+c$

The R-squared value is 0.721 , indicating that $72.1 \%$ of college students' continued learning intention toward E-learning space can be explained by the above linear relationship. From the linear equation, it shows that the satisfaction $X_{6}$ linear coefficient (0.445) is the largest, suggesting that satisfaction has the greatest influence on college students' intention to continuously use E-learning space, 
followed by perceived usefulness (0.243), expectation confirmation (0.141), and perceived ease of use (0.081). Besides, the linear coefficient of students' initial intention (0.073) shows that it has the least positive influence on college students' intention to use the E-learning space consistently.

\section{Mediating effect model test}

In the above layer-by-layer linear regression, it was found that when perceived usefulness and satisfaction were introduced into the linear model, the Beta values of perceived ease of use and expectation confirmation changed significantly. According to the theory related to the continuous use of information systems, perceived usefulness and satisfaction have a mediating effect on users' intention to continuously use by influencing system users' expectation confirmation and satisfaction. In order to further investigate the mediating effect of perceived usefulness and the influence of the mediating effect of perceived usefulness and satisfaction on college students' intention to use the E-learning space continuously, the SEM structural equation model was constructed with AMOS26.0, as shown in Figure 4.

Before the structural equation analysis, the fit test is first performed for the model, and the relevant fit indicators are obtained by AMOS 26.0 analysis: the cardinality freedom ratio value of 2.322 , which is smaller than the reference standard value 3 (Wu, 2009), indicating that the overall model fit is ideal; the absolute fit index value of RMR is 0.018 , which is smaller than the reference standard value of 0.05 ; the GFI value of 0.873 ; the value-added fit degree indexes (CFI $=$ $0.954, \mathrm{NFI}=0.923, \mathrm{IFI}=0.955, \mathrm{TLI}=0.945)$ are greater than the reference standard value $(\mathrm{Wu}, 2009)$ 0.9; parsimony fit index PCFI $=0.786$, PNFI $=0.760$, which are greater than the reference standard value $(\mathrm{Wu}, 2009) 0.5$, indicating that the overall fit of the structural equations is good. The coefficients of each path of the structural equation model and the standard error (SE) and test statistic (CR) of each path are shown in Table 6.

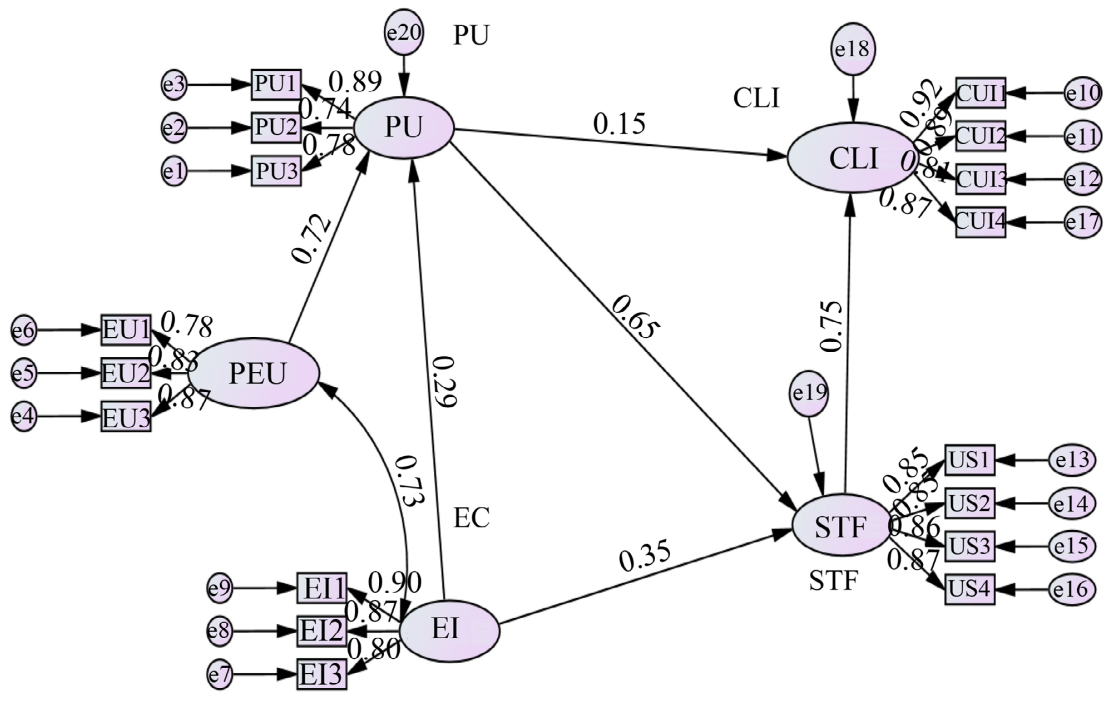

Figure 4. Mediated effects structural equation model. 
Table 6. Path coefficient of structural equation.

\begin{tabular}{|c|c|c|c|c|c|c|}
\hline & path & & $\begin{array}{c}\text { Nonstandard } \\
\text { coefficient }\end{array}$ & $\begin{array}{l}\text { Standard } \\
\text { coefficient }\end{array}$ & S.E. & C.R. \\
\hline $\begin{array}{l}\text { Expectation } \\
\text { confirmation }\end{array}$ & $\rightarrow$ & $\begin{array}{l}\text { Perceived } \\
\text { usefulness }\end{array}$ & 0.230 & 0.286 & 0.059 & 3.884 \\
\hline $\begin{array}{l}\text { Perceived } \\
\text { ease of use }\end{array}$ & $\rightarrow$ & $\begin{array}{l}\text { Perceived } \\
\text { usefulness }\end{array}$ & 0.593 & 0.717 & 0.070 & 8.427 \\
\hline $\begin{array}{l}\text { Expectation } \\
\text { confirmation }\end{array}$ & $\rightarrow$ & satisfaction & 0.336 & 0.354 & 0.073 & 4.628 \\
\hline $\begin{array}{l}\text { Perceived } \\
\text { usefulness }\end{array}$ & $\rightarrow$ & satisfaction & 0.770 & 0.651 & 0.100 & 7.701 \\
\hline satisfaction & $\rightarrow$ & $\begin{array}{c}\text { Continued } \\
\text { learning } \\
\text { intention }\end{array}$ & 0.939 & 0.751 & 0.225 & 4.184 \\
\hline $\begin{array}{l}\text { Perceived } \\
\text { usefulness }\end{array}$ & $\rightarrow$ & $\begin{array}{c}\text { Continued } \\
\text { learning } \\
\text { intention }\end{array}$ & 0.218 & 0.148 & 0.262 & 0.834 \\
\hline
\end{tabular}

After the model test, according to the constructed mediation model, the mediation effects within this model can be divided into mediation effects of perceived usefulness on perceived ease of use and desired confirmation; mediation effects of satisfaction degree on perceived ease of use and desired confirmation; and chain mediation effects of perceived usefulness and satisfaction on perceived ease of use and desired confirmation. Bootstrap was used to test the mediating effect of perceived usefulness and satisfaction, and the path coefficients of each mediating effect, with $90 \%$ confidence intervals, significance and effect values of each path were obtained by re-sampling analysis of 209 valid samples with bootstrap for 2000 times as shown in Table 7.

After the model test, according to the constructed mediation model, the mediation effects within this model can be divided into mediation effects of perceived usefulness on perceived ease of use and desired confirmation; mediation effects of satisfaction degree on perceived ease of use and desired confirmation; and chain mediation effects of perceived usefulness and satisfaction on perceived ease of use and desired confirmation. Bootstrap was used to test the mediating effect of perceived usefulness and satisfaction, and the path coefficients of each mediating effect, with $90 \%$ confidence intervals, significance and effect values of each path were obtained by re-sampling analysis of 209 valid samples with bootstrap for 2000 times as shown in Table 7.

It shows that the mediating effect of perceived usefulness on college students' expectation confirmation and perceived ease of use on continued learning intention is not significant, hypothesis 7 and 8 are not valid; the mediating effect of satisfaction on expectation confirmation on continued learning intention is significant at $90 \%$ confidence interval (effect value $0.226, p=0.016<0.05$ ), hypo- 
thesis 9 is valid; the mediating effect of satisfaction on perceived usefulness on intention to continue using (effect value $0.489, p=0.006<0.05$ ), hypothesis 10 is valid; perceived ease of use significantly affects continued learning intention through the chain mediated utility of perceived usefulness and satisfaction (effect value $0.350, p=0.005<0.05$ ), hypothesis 11 is valid; expectation confirmation significantly affects continued learning intention through the chain mediated utility of perceived usefulness and satisfaction (effect value $0.350, p=$ $0.005<0.05$ ), hypothesis 11 is valid; expectation confirmation significantly affects continued learning intention through the chain mediated utility of perceived usefulness and satisfaction Hypothesis 12 is valid; expectation confirmation significantly affects college students' intention to continue using E-learning space through the chain mediation effect of perceived usefulness and satisfaction. In summary, the results of the direct-action linear model and the perceived usefulness and satisfaction mediated effect model are shown in Figure 5.

Table 7. Standardized bootstrap mediated effects test.

\begin{tabular}{|c|c|c|c|c|c|c|c|c|}
\hline \multirow{2}{*}{ Parameter } & \multirow{2}{*}{ SE } & \multirow{2}{*}{$\begin{array}{l}\text { Effect } \\
\text { Value }\end{array}$} & \multicolumn{3}{|c|}{ Bias-corrected $90 \% \mathrm{CI}$} & \multicolumn{3}{|c|}{ Percentile $90 \%$ CI } \\
\hline & & & Lower & Upper & $\mathrm{P}$ & Lower & Upper & $\mathrm{P}$ \\
\hline stdIndPU1 & 0.000 & 0.000 & 0.000 & 0.000 & Invalid & 0.000 & 0.000 & Invalid \\
\hline stdIndPU2 & 0.000 & 0.000 & 0.000 & 0.000 & Invalid & 0.000 & 0.000 & Invalid \\
\hline stdIndUS1 & 0.124 & 0.266 & 0.093 & 0.494 & $0.016^{* * *}$ & 0.070 & 0.464 & $0.025^{\star * *}$ \\
\hline stdIndUS2 & 0.533 & 0.489 & 0.272 & 0.895 & $0.006^{* * *}$ & 0.226 & 0.791 & $0.013^{* * *}$ \\
\hline stdIndPUUS1 & 0.318 & 0.350 & 0.172 & 0.638 & $0.005^{\star * *}$ & 0.139 & 0.569 & $0.012^{* * *}$ \\
\hline stdIndPUUS2 & 0.240 & 0.140 & 0.072 & 0.336 & $0.004^{* * *}$ & 0.052 & 0.266 & $0.015^{\star * *}$ \\
\hline
\end{tabular}

Note: stdIndPU1: PEU $\rightarrow$ PU $\rightarrow$ CLI; stdIndPU2: EC $\rightarrow$ PU $\rightarrow$ CLI; stdIndUS1: EC $\rightarrow$ STF $\rightarrow$ CLI; stdIndUS2: PU $\rightarrow$ STF $\rightarrow$ CLI; stdIndPUUS1: PEU $\rightarrow$ PU $\rightarrow$ STF $\rightarrow$ CLI; stdIndPUUS2: $\mathrm{EC} \rightarrow$ PU $\rightarrow$ STF $\rightarrow$ CLI.

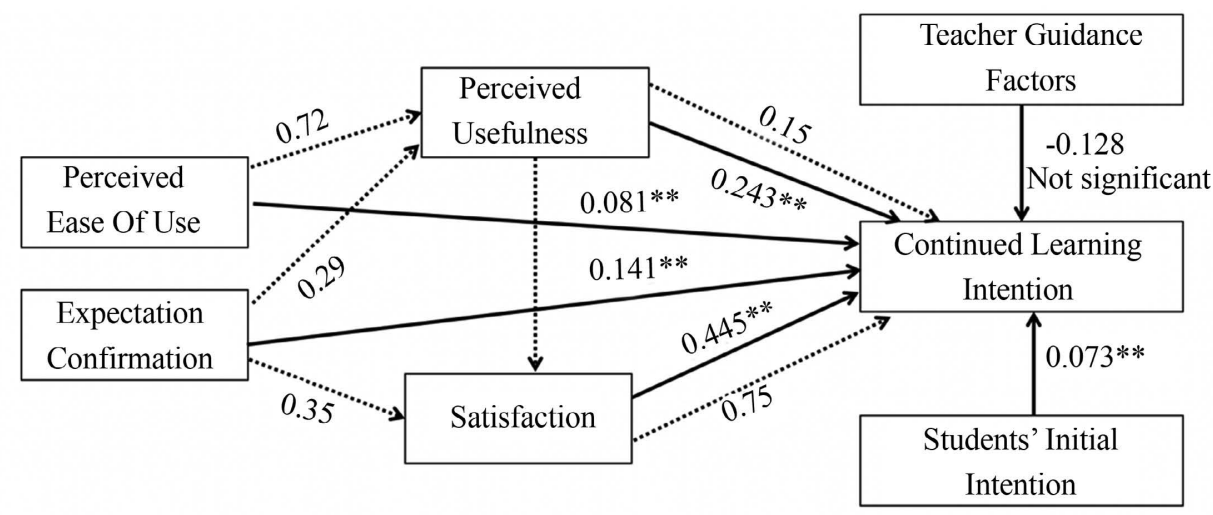

$\begin{aligned} \longrightarrow & \text { Direct Role } \\ \cdots \cdots \cdots \cdots \cdots \cdots & \text { Intermediary Effect }\end{aligned}$

Figure 5. Model test results. 


\section{Research Conclusions and Suggestions}

\subsection{Conclusions}

Based on the theory of ECM-ISC, this study identified perceived ease of use (Beta $=0.081$ ), expectation confirmation (Beta $=0.141$ ), perceived usefulness (Beta $=0.243$ ), and satisfaction (Beta $=0.445$ ) as the core latent variables positively affecting college students' continuous intention to use E-learning space and introduced the teacher guidance factor and the students' initial intention to use the space as new latent variables.

The teacher guidance factor (Beta $=-0.128$ ) on college students' intention to use E-learning space consistently was negatively correlated. According to the results of the questionnaire, $87.38 \%$ of college students in this study used E-learning space consistently, because they had to submit course assignments, $60.18 \%$ and $44.39 \%$ of students viewed course announcements and downloaded course materials respectively, but only $24.3 \%$ of students wished to learn about course content knowledge that interested. It indicates that if teachers only migrate teaching resources and course materials to online spaces but neglect the development of courses and the rational use of E-learning space resources, college students' subjective demand for using E-learning space will be reduced by the eventual return of courses in person.

Besides, from the results of empirical analyses, the linear regression determined the importance of college students' initial intention (Beta $=0.073$ ) to use the E-learning space, and there was no significant difference between college students' gender, grade, and major category on their continuous intention to use the E-learning space.

In addition, according to the survey, nearly $60 \%$ of college students use the E-learning space for less than one hour each time. The main motivation for them using the E-learning space is uploading coursework, downloading materials, and signing in for classes while only $28 \%$ of college students use the E-learning space to organize and manage their learning progress. It suggests that college students fail to reasonably exploit the support role of the E-learning space for learning. Finally, the structural equation model shows that satisfaction and perceived usefulness, as mediating latent variables, plays a crucial role in regulating students' intention to use the E-learning space.

\subsection{Suggestions}

As the transmitter of students' culture and knowledge, teachers play a very important role in leading students to adapt to the future development of information-based society, innovate and change their learning style, and construct knowledge. Therefore, teachers are expected to play the positive value of continuously guiding students to use E-learning space, make reasonable use of the advantages of E-learning space platforms, actively publish refined and efficient course resources, guide students to actively use E-learning space to support their learning, organize necessary training on the use of E-learning space, instruct 
students to make reasonable use of the high-quality E-learning resources grafted to spaces for learning.

Teachers should stimulate students' interest in using E-learning resources in order to gradually build students' confidence and awareness of independent learning. Besides, teachers can tailor their learning strategies to students' characteristics and their problems in independent learning in order to help students adapt to the E-learning space environment and master the learning methods. At the same time, teachers tend to carry out rich learning activities, by leading students in thematic learning, discussion learning, and hands-on learning activities, thus improving students' independent learning skills.

Meanwhile, teachers should pay attention to the comprehensive evaluation of students' independent learning process, rather than giving them a summative evaluation. On the one hand, the E-learning space has the characteristics of interactivity, large capacity and multiple interfaces, teachers should regularly evaluate students' stage learning, affirm and praise students' good performance. On the other hand, teachers need to master scientific and reasonable evaluation methods, maintain a patient attitude, adhere to the principles of fairness and impartiality, and establish a good teacher-student relationship.

After the period of "stopping classes without stopping learning", college students are encouraged to change their learning concepts, make good use of E-learning platforms, improve their awareness of online resources for learning, and innovate and transform their learning styles. At the same time, it is important to strengthen the practice of using E-learning space to expand knowledge and improve college students' information literacy drawing on the data and interactive advantages of E-learning space.

As a kind of information system with great "educational" attributes. Therefore, the construction of the E-learning space should be "learner-centered", taking the enhancement of learners' perceived usefulness as the guide. Meanwhile, the E-learning space should be designed in accordance with learners' learning style and habits, providing more efficient information screening and resource acquisition strategies, enhancing learners' expectations and satisfaction of using the E-learning space to promote learners' subjective continuous learning behavior.

\section{Acknowledgements}

This research was supported in part by a grant from 2019 Anhui Social Science Planning Project "Research on Knowledge Supply and Guidance Mechanism for Deep Learning in the Internet Age" (No. AHSKY 2019D036).

\section{Conflicts of Interest}

The authors declare that there is no conflict of interests regarding the publication of this article.

\section{References}

Bhattacherjee, A. (2001). Understanding Information Systems Continuance: An Expecta- 
tion Confirmation Model. MIS Quarterly, 25, 351-370. https://doi.org/10.2307/3250921

Bhattacherjee, A., Perols, J., \& Sanford, C. (2008). Information Technology Continuance: A Theoretic Extension and Empirical Test. Journal of Computer Information Systems, 49, 17-26. https://doi.org/10.1080/08874417.2008.11645302

Chen, M., Bai, X., \& Lin, Y. (2014). An Empirical Study on the Factors Influencing the Continuous Use Behaviour of Mobile Learning Users. China Distance Education, No. 12, 41-47.

China Internet Information Center (2020). The 48th China Internet Network Development Statistics Report. China Internet Information Center. http://www.cnnic.cn/hlwfzyj/hlwxzbg/hlwtjbg/202109/P020210915523670981527.pdf

Davis Jr., F. D. (1986). A Technology Acceptance Model for Empirically Testing New End-User Information Systems: Theory and Results. Massachusetts Institute of Technology.

Davis, F. D. (1989). Perceived Usefulness, Perceived Ease of Use, and User Acceptance of Information Technology. MIS Quarterly, No. 3, 319-340. https://doi.org/10.2307/249008

Li, Z., \& Guo, S. (2017). A Theoretical Model and Empirical Study on the Sustained Use of Archival WeChat Public Users. Archival Research, No. 2, 80-88.

Limayem, M., Hirt, S. G., \& Cheung, C. M. K. (2007). How Habit Limits the Predictive Power of Intention: The Case of Information Systems Continuance. MIS Quarterly, 31, 705-737. https://doi.org/10.2307/25148817

Lin, C. S., Wu, S., \& Tsai, R. (2005). Integrating Perceived Playfulness into Expectation-Confirmation Model for Web Portal Context. Information \& Management, 42, 683-693. https://doi.org/10.1016/j.im.2004.04.003

Liu, L., \& Sun, K. (2011). A Theoretical Model of Continuous Use of Mobile Search Users Based on Extended ECM-ISC. Library Intelligence Work, No. 20, 134-137+148.

Ministry of Education, China (2019). Notice of the Ministry of Education on Releasing the Guidelines for the Construction and Application of Online Learning Spaces.

Ouyang, B., Liu, K. F., \& Yang, H. J. (2017). A Review of Foreign Information System Continuous Use Model Application Research. Modern Intelligence, No. 8, 171-177.

Park, J. H. (2014). The Effects of Personalization on User Continuance in Social Networking Sites. Information Processing Management, 50, 462-475. https://doi.org/10.1016/j.ipm.2014.02.002

Shiau, W.-L., \& Luo, M. M. (2013). Continuance Intention of Blog Users: The Impact of Perceived Enjoyment, Habit, User Involvement and Blogging Time. Behaviour Information Technology, 32, 570-583. https://doi.org/10.1080/0144929X.2012.671851

Turel, O., \& Gefen, D. (2013). The Dual Role of Trust in System Use. Journal of Computer Information Systems, 54, 2-10. https://doi.org/10.1080/08874417.2013.11645666

Wu, M. L. (2009). Structural Equation Modelling an Operation and Application of AMOS. Chongqing University Press.

Xie, Y., Sheng, C., Yang, X. et al. (2016). A Study on the Effect of Online Learning Space to Enhance Self-Efficacy. China E-Learning, No. 1, 34-40.

$\mathrm{Xu}$, L., \& Zhu, D. Q. (2019). An Empirical Study of Students' Acceptance of Online Learning Space in Vocational Colleges and Universities. Tsinghua University Education Research, No. 6, 109-116.

Yang, B., \& Wang, K. D. (2018). Study on the Construction of Teaching Application Model of Online Learning Space DPSC One of the Practical Reflections on Promoting 
Deep Change of Teaching and Learning by Online Learning Space for All. China's Electrochemical Education, No. 5, 44-52.

Yang, W. C. (2015). An Empirical Study on the Continuous Use Behaviour of Digital Education Resources Users-Based on the Extended ECM_ISC Model. China's Electro-Chemical Education, No. 11, 54-61+85.

Yang, Y., \& Wu, L. (2016). Innovative Application Model of Online Learning Space in the Perspective of Ubiquitous Learning. China's Electronized Education, No. 7, 29-35.

Yong, W. J. (2018). An Empirical Study of Students' Learning Satisfaction in Vocational Education E-Learning Spaces. China E-learning, No. 4, 66-71.

Zhang, S. (2016). A Study on the Factors Influencing the Use of Online Learning Spaces by Primary and Secondary School Teachers-An Investigation Based on the UTAUT Model. China's Electro-Chemical Education, No. 3, 99-106.

Zhu, Z. (2013). Framework for the Construction of Net Final Learning Space for All. China's Computerized Education, No. 10, 1-7. 